\title{
The Application of Translation Workshop to Translation Teaching for Non-English Majors
}

\author{
Juju Wang \\ School of Foreign Studies, Qi Lu Normal University, Ji Nan, Shandong, China \\ torchwang@126.com
}

\begin{abstract}
Keywords: Translation teaching; Translation workshop; Non-English Major in College
\end{abstract}
\begin{abstract}
This paper explored the feasibility and advantages of the application of translation workshop to translation teaching. According to the features of translation workshop and translation teaching in college the author designed specific teaching procedures: preparing step before the class, management during the class and evaluating step after the class. Teacher centered model was switched into the students-oriented one, and students' practicing and cooperating abilities were focused and encouraged. Some suggestions were advanced last in order to stimulating students' interests and promoting their translation skills.
\end{abstract}

\section{Introduction}

The research on translation teaching from both home and abroad tended to be diversified for the few decades which have witnessed different researchers explored various effective translation teaching methods and strategies from different perspectives in order to optimize the teaching process and promote teaching quality. Translation workshop is pragmatic teaching model derived from 1960s in some universities of America. In this model, students constitute workshop and simulate actual translation scenes which are organized by the teacher, and complete particular task with mutual exploration and cooperation. This teaching method was applied widely to some teaching fields in foreign countries and gotten attention by domestic scholars. However, there are few deep and all-round research on this teaching system, and its application to translating teaching is lack of further testing. This paper tried to explore the feasibility and advantages of applying translation workshop to the translation teaching in Chinese university.

\section{Research Status of Translation Workshop Teaching}

Translation workshop was derived in 1960s in some universities of America and generally developed into a pragmatic and process-oriented teaching pattern, which likes the commercial translation center in which two or more translators got together to finish certain translation tasks [1]. Translators communicate with each other to solve the practical problems during translating, and when combined this kind of system with translation class a new translation teaching method was produced. The essence of it is to let students learning by doing, which enable them to learn translation from practice. This conforms to the principle of "practice- recognizance- re-practice". In this teaching mode, teacher is no longer the dominant of the class, while the students' operating and cooperating abilities are focused. The general form of it constitutes team discussion and individual speech parts with teachers' explain and illustration for some problems. As a teaching strategy, this can promote the interaction between teachers and students.

Oversea Research. Translation workshop originated from writing workshop, which formed in many universities in America aimed at promoting literature translation. Latter, it generally entered many western universities' courses. Among all the practical researches, the university of Lowa was considered as the pioneer and most influential one in which some practical courses were designed for the art masters in literature of theatre and television college in the form of translation workshop mode. This teaching mode not only encouraged students to discuss the form and content of literature works in group but also 
to analyze the original intention of the literature together. In such class, students should be completely concerned of the relationship of writer and literature, writer and translator, translation texts and target readers.

What's more, students in translation workshop could cooperate with colleague from different schools and subjects and the international visiting scholars. For the workers in workshop, translation theory was a crucial part, but the art masters in the university of Lowa paid more attention on western traditional translation history. Besides the courses provided by the workshop, students could also study some individual translation features.

Nowadays, translation workshop has efficiently used in cultivating students practical abilities, while its form has changed correspondingly. Internet translation workshop is a good case in point, which is open for 24 hours a day and is helpful for translators' interactions. Yet standard processing chain and available resources are in need [2].

Domestic Research. Translation workshop was lagged behind compared with western country's situation., which serves as one of the teaching strategies in Only a few universities up to now. In recent years, translation has shown its increasing importance in Chinese economic growth and cultural political reforms, and there is more requirement for translation talents at the same time. The State Council issued the document On Setting up Professional Master Degree of Translation in 2007, and MTI professional degrees were set from then on. In this document, applying workshop as an effective teaching method has been highlighted.

The research and application of translation workshop in Taiwan and Hongkong was earlier than in Chinese mainland. A series of speeches about translation workshop was held in Taiwan University, in which scholars from various professions declared their opinions with the goal to promote the translation cultural reform and workshop's application in higher education. In the following years, related courses were established in Taiwan University, Taiwan Normal University. In CUHK, the curriculum of bachelor and master all applied workshop as the main teaching mode. Professor Jin Shenghua designed specific teaching procedures and received remarkable results.

The Chinese to English course in East China Normal University, a professional basic course, has been undergoing a series of reforms which switched class into a translation workshop. Established in 2005, this course has been awarded as the classical course in Shanghai, and national classical course in 2009, the first prize of teaching achievements in Shanghai.

Some scholars and teachers illustrated their points about the translation workshop in recent years. Xiao Hong cites the advantage of translation workshop is to advance the interaction between teachers and students, promoting students' interests in translation, create joyous teaching environment, embody students' subjectivity in thinking and solving problems [3].

Chen Xiuwen advocated learners to take advantage of internet and other possible resources in the form of workshop, and team coordinating effects in promoting learner's translation skills [4].

Zhu Huifen considered translation workshop mode can applied in vocational schools as well as other professional education to boost student's practical translation skills [5].

\section{Teaching Procedure of Translation Workshop for English Major}

Translation workshop teaching procedure consists 3 steps according to the characteristics of translation workshop and English major's education. The first step, preparing stage, requires teachers to demonstrate abundant translation materials, theories and skills; managing step is the second one, in which students need to complete translation tasks through coordination. Last part is conclusion step, and teacher organizes students to discuss and evaluate each groups' works.

Before the Class. Translation workshop was lagged behind compared with western country's situation., which serves as one of the teaching strategies in Only a few universities up to now. In recent years, translation has shown its increasing importance in Chinese economic growth and cultural political reforms, and there is more requirement for translation talents at the same time. The It is widely acknowledged that perfect and meticulous preparation is necessary for translation teaching. In translation workshop, teacher should search plenty of related materials and design each particular 
procedure to let students be familiar with translation contents and relevant translation strategies and skills.

This step constitutes of teacher's presentation and student's knowledge preparation. Teacher can spend about 20 minutes to illustrate translation basic knowledge or the basic problems about translation, and highlight the stressed and difficult points. When it comes to translation theory, translation principle and standard, skills, basic information of stylistic translation are the priority. When training students' skills, common used translation skills should be introduced briefly and clearly.

Suppose the students major in hotel management or travel management, material collection should be link with their majority including usual documents about customs, tour guide, exit and entry, and various external commercial documents. What's more, teacher should guarantee the translation task is based on collected materials and consider the possible translation skills when students dealing with all the stuff and the need for future job after graduation.

Teacher can start the class off with introducing some samples which should be analyzed accurately and precisely. Teacher is encouraged to interact with students, stimulate them to ask questions, discuss the similarity and distinct translation strategies compared with other texts.

Amplification, omission, negation etc. Translation skills also can be introduced for the students in order to improve students' translation abilities.

During Translation

During the Class. In translation workshop, students are the center of the class and divided into various groups to finish different tasks. Teacher plays important role in managing and controlling the whole teaching process. After the preparation step, students begin to translate while teacher should go great lengths to guarantee harmonized and active environment.

After teacher's necessary illustration, students can read and try to understand practice materials. Teacher can guide students to explore, discover and withdraw important knowledge and special information. After reading, students can be divided into different groups to discuss in order to solve linguistic problems and obstacles, to transcend the cultural gap between English and Chinese. The joint activity with the same purpose will stimulate students' translation interest and give full play to their creativity and collective wisdom. They can make figure out some obscure culture-loaded words, the literal and implicated meanings, figurative language, and finally thoroughly understand the thoughts of original texts. The next step is correct expression which should be finished independently in a set time by the student, and teacher can supervise and organize students' translation activity without interfering.

After the Class. In this stage, all groups' tasks are finished and teacher should conduct them to evaluate their work. Evaluation is necessary to translation workshop, which enable students to handle such kind of materials.

This part consists of modification and evaluation. Modification can be completed in pairs who can appreciate each translation and compare with the original one to check whether there are obscure and improper part. Each group can elect the best translation and read it before the class, while the rest of the students can point out the merit and demerit for further modification. Teacher can guide and evaluate their discussion and modification and lead them to translate better and conclude the translation experience and principles. Teacher also should praise an encourage them, and if necessary some reward mechanism may make the process complete and interesting.

\section{Summary}

Chinese translation teaching appeared to be diversified in these decades, and different researchers explore and study all kinds of translation methods in order to train translation talents who are more suit for the social requirements. Translation workshop can be applied in college English teaching for non-English majors, which can be practical and effective compared with traditional teaching method. It cannot only promote learner' translation skills but also their translation interests. College English teachers can use various teaching strategies to advance teaching quality. Based on the statement of this strategy, more empirical study is need to test its efficiency in the future. 


\section{Acknowledgement}

A Phased achievements of the "Study on the Teaching Strategies for Undergraduates Based on Learning Style" of Shandong social sciences planning study program (16CZWJ55).

\section{References}

[1] Gentzler, Edwin: Contemporary Translation Theories (Routledge Publications, London 1993).

[2] Ghaith, G : Bilingual Eductioin and Bilingualism, Vol.7 (2004)

[3] H. Xiao : Journal of Sichuan International Studies University, Vol. 2 (2005)

[4] X. W. Chen: Proc. 23th North American Conference on Chinese Linguistics (University of Oregon, USA, November 8-10, 2011).

[5] H.F. Zhu : Journal of Electronic Science and Technology, Vol. 1 (2007)

[6] Leandro, Wolfson : Psychological Bulletin, Vol.89 (1981)

[7] Serena, Jin : Journal of Translation Studies, Vol.4 (2004)

[8] Ghaith, G : Bilingual Eductioin and Bilingualism, Vol.7 (2004)

[9] A.D. Chen: English and Chinese Comparation and Translation (China Translation and Publication Corporation, China 2000).

[10] C.B. Zhang, B. Wu: Foreign Teaching Theory and Practice, (2011)

[11] Y.R. Chen :Education Teaching BBS, Vol.4 (2012)

[12]L. Mu: Chinese Translation Teaching Research (Shanghai Foriegn Language Education Press, China 1999). 